\title{
INDÍCIOS DE DESENVOLVIMENTO EM CRIANÇAS COM DEFICIÊNCIA VISUAL E PROBLEMAS NEUROLÓGICOS
}

INDICATIONS OF DEVELOPMENT IN CHILDREN WITH VISUAL IMPAIRMENT AND NEUROLOGICAL PROBLEMS

\author{
Michelli Alessandra SILVA ${ }^{1}$ \\ Cecília Guarnieri BATISTA²
}

\begin{abstract}
RESUMO: a literatura aponta que crianças com diagnóstico de deficiência visual e outras deficiências associadas estão em risco de desenvolvimento. No presente estudo, foram observadas três crianças com esse perfil (quatro a 10 anos), no contexto de grupos de convivência, com o intuito de identificar indícios de desenvolvimento e exemplos de apropriação de práticas sociais. Deu-se destaque aos diferentes usos de objetos, à participação em atividades e à linguagem como lugares para se observar esses processos. Foi realizado estudo de caso e análise microgenética. As sessões semanais foram filmadas e transcritas. Recortou-se o material documentado em episódios que fossem significativos para o propósito do estudo. A análise evidenciou a importância dos processos de significação na constituição dos sujeitos. Os resultados foram discutidos em termos de suas implicações para programas de intervenção.
\end{abstract}

PALAVRAS-CHAVE: Educação Especial. Mediação Semiótica. Linguagem. Deficiência visual. Alterações no Desenvolvimento.

\begin{abstract}
: studies on the development of children with visual impairment associated with other disabilities indicate risks for development. In the present study, three children with this profile (aged four to 10 years) were observed in social group contexts. The aim was to identify indications of development and examples of appropriation of social practices. In order to visualize those processes, the study focused on different uses of objects, participation in activities and language. A case study and microgenetic analysis were carried out. Weekly sessions were filmed and transcribed; episodes were selected from the material that had been registered according to relevance related to the purpose of the study. The analysis showed the importance of signification processes for the constitution of subjects. The results were discussed in terms of implications for intervention programs.
\end{abstract}

KEYWORDS: Special Education. Semiotic Mediation. Language. Visual Impairment. Developmental Alterations.

\section{INTRODUÇão}

A literatura vem ressaltando os riscos para o desenvolvimento que podem ser originados a partir de diferentes condições orgânicas, das quais se destaca, no presente trabalho, a deficiência visual associada a alterações neurológicas. Em relação a crianças com deficiência visual, diferentes estudos apontam possíveis riscos ao desenvolvimento. Buscando traçar o perfil funcional de crianças com deficiência visual, Alon et al. (2010) realizaram um estudo com 18 crianças com deficiência

\footnotetext{
${ }^{1}$ Mestre em Saúde da Criança e do Adolescente - Faculdade de Ciências Médicas - UNICAMP. michelli.br@ terra.com.br.

${ }^{2}$ Doutora em Psicologia- USP/Docente do CEPRE - Faculdade de Ciências Médicas - UNICAMP. cecigb@fcm. unicamp.br
} 
visual severa e 21 crianças com atraso no desenvolvimento motor e linguístico, entre seis e 36 meses de idade; também foi incluído na pesquisa um grupo de controle. Os autores verificaram que, comparadas aos dois outros grupos estudados, as crianças com deficiência visual severa apresentam dificuldades mais significativas em relação a fatores de reação sensorial, organizacional e comportamental; e chegaram à conclusão de que crianças com deficiência visual severa parecem ter uma prevalência no aumento e severidade de desordens de regulação ${ }^{3}$.

Celeste (2006), em estudo de caso de uma criança cega, na idade préescolar nos Estados Unidos, constatou um comprometimento das competências sociais: a criança demonstrou predominantemente brincadeiras solitárias e, quando participou de situações interativas, deu preferência a adultos, em relação aos seus pares. A autora atribuiu este comprometimento ao fato de crianças com deficiências receberem menos respostas positivas aos apelos sociais ou às tentativas de interações sociais. O mesmo foi descrito por Preisler (1997), em estudo longitudinal abrangendo nove crianças cegas congênitas na Suécia. Em ambos os estudos, crianças cegas, com bom desenvolvimento cognitivo, tiveram dificuldades de se engajar em atividades sociais com seus pares videntes, provavelmente com decorrências negativas para o desenvolvimento de habilidades sociais. Os diferentes estudos apontam para a necessidade de atenção à promoção do desenvolvimento global e, especialmente, social, de crianças com deficiência visual.

A deficiência visual pode estar associada a questões sociais e emocionais. Ophir-Cohen et al. (2005) estudaram 210 crianças com deficiência visual, que apresentavam ou não déficits emocionais, comportamentais ou ambos. Os autores verificaram um comprometimento mais acentuado no desenvolvimento das crianças com deficiência visual que apresentavam déficits emocionais e/ou comportamentais. Ophir-Cohen et al. (2005) destacam a importância de uma intervenção ainda nos primeiros meses de vida, que propicie o desenvolvimento emocional e comportamental e, consequentemente amplie as possibilidades de desenvolvimento dessas crianças.

Uma outra discussão trazida pela literatura está relacionada ao fato de crianças cegas terem maior probabilidade de apresentar autismo (conforme caracterizado por BOSA; CALLIAS, 2000), ou comportamentos semelhantes aos de autistas (autistic-like behaviors). Uma das razões apresentadas relacionase ao fato dessas crianças, em função do baixo nível de estimulação visual ou mesmo ausência desta, buscarem maior estimulação por outras vias sensoriais e proprioceptivas. Essa busca, que inclui o feedback advindo de movimentos cíclicos, pode levar a um padrão de auto-estimulação, semelhante ao observado em autistas (WARREN, 1994). Entretanto, diferentemente do caso do autismo, verifica-se, na maioria dos casos, uma redução desses comportamentos em idades mais avançadas. Em estudo com 24 crianças cegas congênitas, Hobson et al. (1997)

3 Os autores definem desordem de regulação como um déficit nos padrões comportamentais associado a dificuldades nos processos sensoriais, sensoriomotores ou organizacionais que resultam em dificuldades na adaptação e interação da criança com seu ambiente. 
verificaram que a maioria apresentou alguns comportamentos semelhantes aos de autistas, por exemplo, no que se refere à sensibilidade aos sinais comunicativos de outras pessoas. Entretanto, o diagnóstico formal de autismo, pelo DSM-III, foi atribuído a aproximadamente um terço das crianças (10 das 24 crianças estudadas), indicando que existe um número maior de crianças cegas que apresentam alguns comportamentos semelhantes aos de autistas, do que crianças com o diagnóstico específico de autismo. Ao analisar os dados, e buscando explicá-los como em parte relacionados a fatores psicológicos, os autores apontam, dentre estes, tanto aspectos cognitivos (ligados à representação) como sociocomunicativos (ligados a intersubjetividade). Desse modo, embora o autismo não seja inerente à deficiência visual, crianças com essa deficiência tendem a apresentar mais comportamentos repetitivos, de autoestimulação, que podem levar ao desenvolvimento de padrões de isolamento social e alterações no processo de desenvolvimento global.

Em relação ao autismo, a literatura tende a apontar a predominância de fatores congênitos; entretanto, vários estudos sugerem a interação dos mesmos com fatores ambientais. Bosa (2002), em revisão de literatura sobre o autismo em crianças videntes, ressalta, entre outros aspectos psicológicos, a importância da relação de apego entre cuidador-criança e as estratégias de interação e sensibilidade aos sinais infantis por parte do adulto. Esse é um aspecto em que as díades mãe-criança estão em risco no caso de cegueira. A interação mãe-bebê pode estar prejudicada, tanto pelas dificuldades de percepção dos sinais comunicativos, quanto pela possível depressão da mãe, conforme discute Warren (1994). Essas possíveis alterações nas interações iniciais podem trazer vários prejuízos para o desenvolvimento da criança cega, não apenas no que se refere ao risco de autismo.

Outro autor que atua na área da deficiência visual, Erin (1996), ressalta o fato de que a presença de outras condições adversas associadas à deficiência visual pode afetar ainda mais o desenvolvimento das crianças. Na mesma direção, WolfSchein (1998) discute que estudantes com deficiência visual e outras deficiências associadas possuem um nível e uma combinação de dificuldades que impedem que eles tenham algumas experiências e oportunidades de aprendizagem incidental. Neste mesmo trabalho, o autor discute a dificuldade de se avaliar crianças com múltiplas deficiências por meio de avaliações mais estruturadas. Dessa forma, ao abordar a questão das crianças que apresentam múltiplos obstáculos congênitos ao desenvolvimento, permanece a questão sobre as formas de abordar esse desenvolvimento. Entre outros aspectos, destaca-se a preocupação em evidenciar indicadores de desenvolvimento, em situações em que tendem a ser ressaltados déficits e dificuldades.

Vygotsky, em seus estudos, enfatizou a importância das interações sociais frente aos obstáculos orgânicos em crianças com deficiências. Ao referir-se ao desenvolvimento de crianças cegas, Vygotsky (1997) ressaltou que, apesar de a cegueira criar dificuldades para a participação em muitas atividades da vida social, não há diferenças básicas no impulso para o desenvolvimento da criança, seja ela cega ou vidente. Afirmou, ainda, que é comum, ao cego e ao vidente, a fonte principal 
de conteúdos de desenvolvimento: a linguagem. Ao destacar a importância da linguagem no desenvolvimento infantil, o autor trouxe, como um dos temas centrais de suas considerações teóricas, a noção de signo como instrumento mediador e constituidor da atividade mental: "um signo é sempre, originalmente, um meio/ modo de interação social, um meio para influenciar os outros e só depois se torna um meio para influenciar a si próprio" (VYGOTSKY, 1997, p. 83).

Essas considerações estão fundamentadas em uma das principais concepções teóricas de Vygotsky (1989): a de que as funções mentais são relações sociais internalizadas. Baseando-se nessa questão central das considerações teóricas do autor, Smolka (2000) sugere uma (re) leitura do termo "apropriação", relacionando-o à idéia de "internalização". A autora identifica internalização como um construto teórico central no âmbito da perspectiva histórico-cultural, que se refere ao processo de desenvolvimento e aprendizagem humana como incorporação da cultura, como domínio dos modos culturais de agir, pensar, de se relacionar com outros, consigo mesmo, e que aparece como contrário a uma perspectiva naturalista ou inatista. Assim, define o conceito de apropriação (compartilhado neste trabalho):

a apropriação não é tanto uma questão de posse, de propriedade, ou mesmo de domínio, individualmente alcançados, mas é essencialmente uma questão de pertencer e participar nas práticas sociais. (...) Nessas práticas, o sujeito - ele próprio um signo, interpretado e interpretante em relação ao outro - não existe antes ou independente do outro, do signo, mas se faz, se constitui nas relações significativas (SMOLKA, 2000, p.37).

Segundo Smolka (2000) isso quer dizer que, não é o que o indivíduo é, a priori, que explica seus modos de se relacionar com os outros, mas são as relações sociais nas quais ele está envolvido que podem explicar seus modos de ser, de agir, de pensar, de relacionar-se. Ressalta ainda, que "não se pode compreender esse processo de formação do funcionamento mental pelas relações sociais a não ser que se considere a produção simultânea de signos e sentidos, relacionada à constituição de sujeitos, na dinâmica dessas (inter-) relações" (p. 31).

Retomando as concepções teóricas de Vygotsky (2000), o autor diz que “o pensamento não é só externamente mediado por signos como internamente mediado por significados" (p.479). Para o autor a comunicação imediata entre consciências só pode ser atingida por "via indireta", por "via mediata". Em seus dizeres "essa via é uma mediação interna do pensamento, primeiro pelos significados e depois pelas palavras" (p.479).

A linguagem, neste contexto, é vista como a via de excelência na qual, com a qual e sobre a qual se estabelecem as relações entre os sujeitos envolvidos no processo de significação (GERALDI, 1990), seja esse processo de significação verbal ou não-verbal. Assume-se, dessa forma, aqui, uma teoria indeterminada e pública de linguagem (FRANCHI, 1992), à luz da qual o sentido não é dado 
a priori - mas se faz em meio a contingências sócio-históricas, incluindo fatores contextuais bem como as manifestações e os recursos utilizados pelos sujeitos. Da aceitação de tal concepção de linguagem decorre a possibilidade de visualizar uma relação dinâmica e constitutiva entre o sujeito, a linguagem, outros sistemas semióticos e outros sujeitos.

Tendo em vista as considerações sobre a constituição social do sujeito e a importância da mediação semiótica no desenvolvimento humano, colocase a questão sobre a possibilidade de identificar indícios de desenvolvimento e processos de apropriação de práticas sociais (SMOLKA, 2000) em crianças habitualmente rotuladas por déficits e incapacidades, como é o caso das crianças enfocadas no presente estudo. O desenvolvimento dessas crianças é caracterizado por uma grande instabilidade, o que dificulta e traz desafios ao estudo. Ainda assim, pretendeu-se identificar esses indícios, observando-se, em contexto de interação, os diferentes usos de objetos, a participação em atividades e a linguagem dessas crianças.

Nesse sentido, contribuições de outros autores foram importantes para a realização deste trabalho. Rodríguez e Moro (1999), em um estudo com seis crianças (nas idades desete, 10 e13 meses), observaram, registraram e transcreveram o momento de interação entre mãe, bebê e objeto. As pesquisadoras enfocaram, ao mesmo tempo, a interação social e o uso que mãe e bebê faziam dos objetos apresentados: um caminhão de plástico que possuía aberturas de formatos diferentes nas quais se encaixavam peças de formato correspondente, e um telefone de brinquedo. As autoras analisaram que a relação do bebê com os objetos não é transparente, nem apenas relacionada a suas propriedades físicas: o bebê vai modificando sua relação com os mesmos, desde usos não canônicos (por exemplo: bater, chupar), até usos mais convencionais (por exemplo: colocar o telefone na orelha) por meio da interação do adulto, que, nas palavras das autoras, "atualiza os usos convencionais e os significados culturais dos objetos através dos signos" (p. 144).

Neste trabalho, o estudo das autoras foi inspirador, uma vez que destacou a importância do objeto na interação com a criança, o que direcionou as observações, entre outros aspectos, para as diferentes formas que as crianças, em estudo, utilizam objetos. Ressalta-se, entretanto, que o estudo das autoras foi realizado com bebês (sete, 10 e 13 meses) com desenvolvimento típico e delimitou-se à observação da interação desses bebês com a mãe e com objetos preestabelecidos (um caminhão de plástico com peças de encaixe e um telefone de brinquedo). Nesta pesquisa, as crianças eram mais velhas (quatro a 10 anos), tinham diagnóstico de deficiências de origem orgânica e apresentavam um processo de desenvolvimento bastante instável. Além disso, foram observadas em grupos de convivência, em que diferentes objetos estavam disponíveis, e dos quais participavam diferentes crianças.

As diferentes maneiras de se utilizar objetos foram tomadas como possíveis indicadores de apropriação das práticas sociais, pelas crianças do presente trabalho. Nesse sentido, as considerações de Sinha (2005), a respeito dos 
objetos do mundo, também se tornaram relevantes. O autor enfatiza os aspectos culturais e históricos presentes nos mesmos, destacando a importância do papel do adulto em interação com a criança, ao ensinar os usos convencionais dos objetos ou atividades. A partir de uma visão social, cultural e materialista do desenvolvimento cognitivo humano, analisa a brincadeira da criança, de forma a dar visibilidade à microgênese dos processos envolvidos, não apenas em relação às estratégias cognitivas, mas principalmente aos papéis sociais, às relações e identidades negociadas pelos participantes na interação social e comunicativa.

Levando-se em consideração as contribuições dos autores citados, tomouse como foco de análise desta pesquisa os diferentes usos de objetos, a participação em atividades e a linguagem das crianças em estudo, como produções a partir das quais se pode observar processos pelos quais as práticas sociais são construídas e modos de interação que podem favorecer o desenvolvimento de crianças com múltiplas deficiências. O objetivo, portanto, foi o de identificar indícios de desenvolvimento e exemplos de apropriação de práticas sociais em situação de interação com adultos, parceiros e objetos, considerando essa situação como contexto para se compreender o desenvolvimento de crianças com deficiências, dentro da perspectiva teórica aqui delineada.

\section{Método}

Do ponto de vista metodológico, o tipo de estudo proposto para a realização desta pesquisa foi o estudo de caso (LUDKE; ANDRE, 1986), com realização de análise microgenética (GÓES, 2000).

Os sujeitos do estudo participavam de um programa integrado de pesquisa e intervenção em um centro universitário, voltado para crianças com deficiência visual ${ }^{4}$. Três crianças foram selecionadas nos grupos, por serem as que apresentavam as alterações mais acentuadas no desenvolvimento. A caracterização das crianças é apresentada a seguir ${ }^{5}$.

$1^{\circ}$ Caso - Júlia: seis anos, cegueira congênita, com Síndrome de Rodrigues (WILLIS; BEIGHTON, 1992), caracterizada por atraso generalizado no crescimento e desenvolvimento. No início da intervenção, não usava objetos de modo convencional e rejeitava objetos e contato físico, conforme descrito em Silva e Batista (2007). No período descrito, apresentava algumas falas (em geral, palavras e frases "cristalizadas") e manipulação de objetos com movimentos repetitivos.

$2^{\circ}$ Caso - Mário: quatro anos, baixa visão (com ptose palpebral e estrabismo) e agenesia de corpo caloso. No início do estudo, sua interação era caracterizada por fazer perguntas recorrentes aos adultos, sem manter diálogo após as respostas,

\footnotetext{
4 Projeto aprovado pelo Comitê de Ética em Pesquisa da Faculdade de Medicina da Universidade Estadual de Campinas - 615/2004.

${ }^{5}$ Os nomes das crianças são fictícios, as idades das crianças são referentes ao início da coleta de dados.
} 
por não se dirigir às outras crianças e por mostrar alheamento nas atividades em grupo. O uso de objeto envolvia pouca exploração e manuseio repetitivo.

$3^{\circ}$ Caso - Letícia: 10 anos, cegueira congênita e paralisia cerebral (alterações discretas na marcha e em movimentos finos). Recusava-se a participar de atividades no grupo e geralmente rejeitava os objetos que a ela eram oferecidos. Apresentava comportamentos repetitivos (automanipulação) e manuseio estereotipado de objetos. Sua linguagem era composta por vocabulário restrito e ausência de diálogos.

\subsection{Procedimento de Coleta e Análise de Dados}

A coleta dos dados foi realizada a partir de um acompanhamento, por um ano, dos grupos de convivência nos quais se buscava inserir as crianças (BATISTA; LAPLANE, 2007). As sessões foram filmadas e transcritas e foram feitas anotações em Diário de Campo. As transcrições foram examinadas, delimitandose episódios para análise (CARVALHO; PEDROSA, 2002). Foram selecionados os episódios relativos a situações potencialmente interativas. Desses episódios, foram escolhidos três para cada criança, nos quais foram observados avanços ou ações que normalmente não eram realizadas por essas crianças. Foi selecionado, para o presente relato, um episódio por criança.

No estudo, deu-se destaque aos modos de utilização de objetos, à participação em atividades e à linguagem das crianças, categorias gerais de análise que foram norteadoras do que observar.

\section{Resultados E discussão}

\section{$1^{\circ}$ Caso - Júlia}

O episódio em análise foi extraído de uma sessão em que Júlia (seis anos, 11 meses) estava explorando o ambiente onde se encontrava (tateava mesas, paredes, armários) até encontrar uma pia com uma torneira (usada para as crianças lavarem as mãos depois de atividades com tintas). O episódio descreve o momento em que Júlia está com as mãos sob a torneira aberta (que a coordenadora havia aberto) e Michelli (pesquisadora), aproximando-se da criança, começa a orientá-la a abrir e fechar a torneira para sair mais ou menos água.

Júlia: com as mãos sob uma torneira aberta de uma pia. Uma música toca ao fundo e Júlia balança o corpo no ritmo da música. Outras crianças conversam e brincam na sala.

Michelli: a água! Vamos lavar a mãozinha na água? (Aproximando-se de Júlia). Júlia: á::gua, é á::gua, é á::gua! (Permanecendo com as mãos sob a água).

Michelli: vamos fechar a torneira, Jú? Dá a mãozinha pra mim (conduz a mão de Júlia até a torneira, fechando-a, juntas). Fechou a torneira, acabou a água. Vamos abrir de novo para a água sair? (Conduz a mão de Júlia até a torneira abrindo-a, juntas). A água! 
Júlia: é á:gua, é á:gua... (repetindo várias vezes). (Júlia permanece com uma das mãos sobre a torneira aberta e outra sob a água).

Michelli: é água que está saindo da torneira. Vamos fechar, para água parar de sair? Vamos fechar? Fecha (segurando na mão de Júlia, fechando um pouco a torneira, juntas). Fechou! Cadê a água, Jú? Diminuiu a água?

Júlia: fe:cha

Michelli: fechou a torneira. Vamos abrir de novo para sair mais água? (Segurando a mão de Júlia abrem, juntas, a torneira). Abriu, abriu!

Júlia: sorri.

Michelli: está saindo mais água, não está?

Júlia: é á:gua... (repete várias vezes). (Com uma mão sobre a torneira e outra sob a água). Eu quero beber água, mãe! (Inclina o corpo aproximando-se da pia, lambe a pia).

Michelli: você está com sede, Jú? Quer beber água?

Júlia: eu quero beber água, mãe!

Michelli: quer, Jú? Vamos lá, então, beber água? Vamos enxugar a mão e vamos lá buscar água para você beber. (Fecha a torneira e enxuga as mãos de Júlia). Essa é água da torneira, Jú. Essa você não pode beber, essa é só para lavar a mãozinha. Vamos lá, vamos buscar a água para você beber. Me dá sua mãozinha (tentando pegar a mão de Júlia que está sobre a torneira).

Júlia: segura a torneira, recusando-se a ir com Michelli.

Michelli: você quer brincar com a torneira ou quer beber água?

Júlia: sozinha, abre a torneira e coloca as duas mãos sob a água.

Michelli: você abriu a torneira, foi Jú?! A Jú está brincando com a água! Abriu a torneira, sozinha!

Júlia: sorri.

Michelli: agora fecha para eu ver! Vamos ver, você abriu, agora eu quero ver você fechar.

Júlia: inclina-se sobre a pia, encosta a língua na pia, permanecendo com as duas mãos sob a água.

Michelli: você está com sede, Jú? Quer beber água? Fechei, e agora? (Fechando a torneira).

Júlia: abre a torneira novamente, sozinha, e coloca as duas mãos sob a água.

Michelli: abriu a torneira, Jú!

Júlia: ri.

Neste episódio, Júlia realiza diferentes usos do objeto (torneira) na interação com Michelli (pesquisadora): permite que a pesquisadora conduza e realize os movimentos de abrir e fechar a torneira, permanece com a mão sobre a torneira sem realizar movimentos, segura na torneira quando se recusa a ir com a pesquisadora buscar água para beber, abre a torneira sozinha.

De acordo com Rodriguez e Moro (1999), a criança, em interação com adulto, vai se apropriando de usos mais convencionais dos objetos. No caso de Júlia, esses diferentes usos, entretanto, não acontecem isoladamente; ao analisar o contexto, percebem-se diversos fatores que constituem a cena: uma música tocava 
na sala no momento e Júlia acompanhava com o balançar do corpo; explorava a água procurando senti-la (o que parecia lhe dar prazer); explorava, sentia a água com as mãos e brincava (houve momentos em que jogou água no rosto) - ria, sorria, vocalizava quando estava em contato com a água. $\mathrm{O}$ adulto, nesse cenário, atribuiu sentido às ações de Júlia: explicava e fazia junto o uso convencional da torneira (abriam e fechavam a torneira para sair mais ou menos água, e o adulto procurava apontar para esses efeitos do abrir e fechar), procurava confirmar suas hipóteses (Júlia falou “eu quero beber água, mãe!" e encostou a língua na pia. Júlia estaria com sede?), explicava que aquela água não podia ser bebida. Esses modos de mediação do adulto são análogos aos descritos por Vygotsky (2000), quando atribui importância fundamental à mediação do outro através da linguagem no desenvolvimento.

Em relação à linguagem, verificou-se que Júlia repetia a fala do outro e utilizava-se de frases que, embora aparentemente cristalizadas, eram adequadas ao contexto (tratava-se de um momento em que estava em contato com a água, a água era o tema). Na interação com a criança, o adulto se utiliza o tempo todo da linguagem, linguagem esta algumas vezes repetida pela criança e (re) significada pelo adulto. Interessante notar que quando a criança fala "quero beber água, mãe!”, o adulto convida a criança a buscar água para beber, mas ela se recusa a ir com o adulto. Embora não esteja descrito no episódio, uma profissional da área da saúde que se encontrava na sala buscou um copo de água para Júlia beber, e ela não bebeu. Entretanto, o fato de Júlia dizer esta frase, relacionada ao contexto de água, mostra as associações possíveis e os processos pelos quais os sentidos e significados podem ser construídos (GERALDI, 1990). Esta frase tem um significado para o adulto, que a interpreta como Júlia estar com sede. Quando a água é ofertada para Júlia, o significado do que falou é demonstrado pela ação do adulto que busca a água para ela beber. Isso mostra, conforme Franchi (1992) afirma, que é pela linguagem que se constroem os sistemas de referência que permitem compreender as coisas do mundo e, dialeticamente, são os sistemas de referência que permitem que a linguagem ganhe sentido. Ainda que não seja o que Júlia quer no momento, esse movimento em que as práticas sociais são vivenciadas fazem parte do processo de construção de significados e os sentidos no processo de interação. É inserida neste contexto de interação em que práticas sociais são vivenciadas, bem como significados e sentidos são compartilhados, construídos e atribuídos, que se torna possível vislumbrar o desenvolvimento dessa criança. Esses processos também são apresentados por Smolka (2000) quando discute, em seus trabalhos, a apropriação de práticas sociais pelas crianças em contexto de interação.

Nesse contexto, portanto, é possível dimensionar o que ocorre no episódio: em interação com o adulto que atribui sentidos, demonstra, explica e faz junto com a criança, verifica-se o jogo das práticas sociais e comunicativas (o adulto faz junto, a criança momentos depois faz sozinha, o adulto valoriza, (re) significa, a criança repete algumas palavras ditas pelo outro e verbaliza uma frase contextual). $\mathrm{O}$ ambiente, por outro lado, favoreceu essas práticas: não se tratava de um ambiente hostil, muito pelo contrário, o ambiente era familiar, outras crianças estavam 
presentes, uma música suave tocava, o adulto permitia a exploração de Júlia e a incentivava. Mas o que este episódio retrata? Retrata um momento de interação em que práticas sociais são realizadas, usos de objetos que envolvem aspectos culturais são realizados (SINHA, 2005), significados e sentidos são construídos e compartilhados, indícios de desenvolvimento são visualizados - a criança utilizase da linguagem: uma linguagem que está relacionada com o contexto e com a produção do outro; realiza diferentes usos do mesmo objeto (torneira): a criança abre e fecha a torneira junto com o adulto, depois sozinha e novamente quando o adulto pede - o que demonstra que, neste momento, a criança está envolvida, está sendo inserida nas práticas ali compartilhadas.

\section{$2^{\circ}$ CASO - MÁRIO}

O episódio em análise refere-se a uma sessão em que Jaime (outra criança do grupo do qual Mário participava) brinca de vendedor de frutas com Paula (profissional da área da saúde), empurrando um carrinho de supermercado de brinquedo, cheio de frutas de plástico. Mário (cinco anos, oito meses) caminha ao lado de Micaela (profissional da área da saúde), em direção a Jaime e Paula.

Mário: qué maçã! (Falando com Micaela, caminhando em direção ao carrinho de frutas com o qual Jaime brincava com Paula).

Micaela: ah, olha lá, o Mário quer uma maçã (dirigindo-se a Jaime).

Paula: tem uma laranja? (Perguntando para Jaime).

Mário: tem laranja? (Aproximando-se do carrinho).

Paula: tem laranja? (Com a mesma entonação de Mário).

Micaela: o Mário quer comprar, Jaime.

Mário: laranja (com a mão na boca).

Micaela: laranja, olha lá (dirigindo-se a Jaime).

Jaime: procura a fruta no carrinho e encontra.

Mário: aproxima-se do carrinho, estende a mão para pegar uma fruta.

Jaime: oferece a laranja para Mário.

Paula: aí!

Mário: (estende a mão para pegar a laranja que Jaime ofereceu. Quando sua mão está próxima da mão de Jaime, vira-se de costas e coloca a ponta da camiseta na boca). Qué comprá.

Micaela: pega a laranja! Você não vai comprar a laranja? (Apontando para a fruta que Jaime continua segurando).

Mário: vira-se e olha para a fruta que Jaime segura, estendendo para Mário.

Paula: pode pegar.

Mário: pega a laranja dada por Jaime e sai de perto.

Micaela: aí, que delícia!

Paula: nossa!

Mário: (caminha em direção a Cecília, que passa). Laranja (olhando para Cecília e segurando a fruta com as duas mãos, explora a fruta e depois, segurando-a, estende o braço em direção a Jaime que continua brincando junto ao carrinho, com Paula). 
Micaela: dá lá, guarda lá para o Jaime vender (apontando para o carrinho que Jaime estava brincando).

Mário: olha para Micaela, segurando a fruta com o braço estendido.

Micaela: põe lá de novo (apontando para o carrinho).

Mário: aproxima-se do carrinho e coloca a laranja dentro.

Em relação à participação na atividade, verifica-se que Mário, ao ver Jaime e Paula brincando de vender/comprar frutas, se interessa e toma a iniciativa de pedir uma maçã, atitude que a criança poucas vezes tem. $\mathrm{O}$ adulto vê nessa iniciativa uma oportunidade para promover a interação de Mário com um parceiro, interação que raramente a criança estabelece. Mário utiliza-se da linguagem de forma contextualizada, repete partes da fala do outro, o que parece ser um recurso utilizado pela criança para chamar a atenção do outro e estabelecer a interação com seu parceiro. Os adultos assumem um papel fundamental nessa interação, atribuindo os papéis para as crianças e buscando estabelecer a brincadeira de 'comprar e vender frutas' entre elas. A importância da mediação do outro no processo de desenvolvimento é enfatizado por Vygotsky $(1997,1998,2000)$ em seus trabalhos sobre o desenvolvimento infantil.

Interessante notar que Mário toma a iniciativa de pedir a fruta, porém, quando se aproxima do carrinho de frutas pedindo laranja e Jaime a oferece, a criança com a mão já próxima da mão de Jaime, retira-a, vira-se de costas e sai. Entretanto, ao virar-se, Mário diz "qué comprá" olhando para Micaela. O adulto nesse momento intervém, sugerindo para a criança pegar a fruta oferecida por Jaime. Ele pega, seguindo a orientação do adulto, e sai, aparentemente evitando a interação mais prolongada com o colega. $O$ interessante, porém, é que apesar de seu afastamento físico, Mário mantém-se na interação através da linguagem. A importância de se observar as manifestações e os recursos utilizados pelos sujeitos no processo de significação é uma questão discutida por Franchi (1992), que contribui para a análise deste episódio, pois possibilita visualizar os caminhos percorridos pela criança, e que nem sempre são os esperados.

Observa-se, portanto, neste episódio, um uso de objeto (pegar a laranja) que está relacionado com práticas sociais (comprar frutas); uso da linguagem relacionado ao contexto e a recursos que a criança utiliza para se fazer entender; e participação da criança em uma atividade lúdica (brincar de comprar/vender frutas), repleta de significados sociais e culturais. Nesse processo, foi possível identificar algumas das possibilidades e alguns dos recursos que a criança lança mão para se fazer entender e estabelecer uma interação, ainda que através do outro (adulto). Destaca-se, no episódio, a mediação do adulto que explica, retoma, sugere, orienta e introduz a criança aos usos convencionais de objetos (RODRÍGUEZ; MORO, 1999; SINHA, 2005) e conceitos relativos a hábitos e costumes que são parte da cultura (por exemplo: compra de frutas), e promove 
a interação com o outro, atribuindo papéis, significando e dando sentido às ações das crianças (GERALDI, 1990).

\section{$3^{\circ}$ CAso - Letícia}

O episódio em análise refere-se a uma sessão na qual Letícia (9 anos, 2 meses) e Michelli (pesquisadora) brincam de roda (brincadeira de conhecimento de Letícia, já diversas vezes realizada com outros adultos). Cecília (coordenadora) filmava a sessão.

Michelli: vamos brincar de "roda, roda"? (Referindo-se a uma canção de roda). Dá as duas mãozinhas para mim... (ficando em frente à Letícia e pegando em suas mãos).

Michelli: "roda, roda, roda..." (cantando). (Michelli e Letícia, de mãos dadas, em frente uma da outra, giram, brincando de roda).

Letícia: é conduzida nos movimentos, participando da brincadeira de forma parcial. Solta uma das mãos e esfrega o braço no rosto.

Michelli: vamos? (Pegando novamente a mão que Letícia havia soltado). "Palma, palma, palma..." (cantando). (Retomam a brincadeira de roda).

Letícia: agacha-se e senta-se no chão, de mãos dadas com Michelli.

Michelli: vai sentar no chão? O chão está sujo...

Letícia: levanta-se e solta o corpo para trás.

Michelli: você quer sentar? (Segurando Letícia pela cintura).

Cecília: acho que ela fez o "peixe é". (Referindo-se ao momento da canção em que se agacha).

Michelli: ah, você fez o "peixe é"? Então vamos fazer... “caranguejo, peixe é!" (cantando o trecho da canção em que se agacha). (Pegando as mãos de Letícia e agachando-se).

Letícia: permanece em pé.

Michelli: como é que é o "peixe é"? (Agachada, segurando as mãos de Letícia).

Letícia: agacha-se e senta-se no chão.

Michelli: aí! Parabenizando Letícia. Só que tem que levantar, não pode sentar! (Segurando as mãos de Letícia e a ajudando a se levantar).

Letícia: levanta- se.

Michelli: aí! (Parabenizando Letícia).

Neste episódio, Michelli (pesquisadora) inicia uma brincadeira que é de conhecimento de Letícia (Letícia já havia brincado de roda, com a canção que Michelli propõe para cantarem, em sessões anteriores). Letícia, no entanto, agachase e senta-se no chão, ação que Michelli interpreta, significa e atribui sentido ("vai sentar no chão? O chão está sujo..."; "quer sentar?"). A pesquisadora interpreta a ação de Letícia como interrompendo a brincadeira de roda, como se Letícia quisesse sentar-se no chão apenas. No entanto, Cecília tem uma interpretação diferente: "acho que ela fez o 'peixe é'!" - Letícia, portanto, está fazendo algo que faz parte da brincadeira de roda, porém em um momento anterior ao feito na 
canção (convencionalmente, agacha-se no final da música). Apesar de inicialmente não estar claro o que Letícia realizou, a atribuição de sentido de Cecília, aceita por Michelli, faz com que a pesquisadora mude sua intervenção e retome a brincadeira. Quando questionada "como é que é o "peixe é'?", Letícia agacha-se e senta-se no chão novamente - o que é (re) significado como sendo o "peixe é".

Aqui, verifica-se a importância da atribuição de significado por parte do outro, que compartilha conhecimentos e vivências com a criança (Cecília já tinha brincado de roda com Letícia em sessões anteriores e sabia que Letícia agachavase, algumas vezes, no momento que se canta "peixe é"). Ainda que não se tenha claro se a ação da criança foi de sentar-se ou de realizar o "peixe é", o fato de o adulto significá-la dessa maneira fez com que se redimensionasse a ação da criança para o contexto da brincadeira, o que propiciou sua continuação e a inserção de Letícia na interação: a criança passa a ser vista como alguém que participa da brincadeira. A análise deste episódio levanta questões já discutidas por Vygotsky (2000) a respeito da importância da mediação do outro e da linguagem no processo de desenvolvimento infantil. Da mesma forma, corrobora as idéias de Franchi (1992) a respeito dos processos de significação verbais e não verbais presentes em situações interativas em que a linguagem torna-se a via de excelência. E também apresenta fatos discutidos por Smolka (2000) a respeito da apropriação de práticas sociais (brincar de roda) em contextos de interação. As contribuições desses autores permitem que sejam visualizados indícios de desenvolvimento, uma vez que possibilita a (re) leitura da criança no contexto de interação, como alguém que participa da atividade proposta pelo adulto, ainda que à sua maneira.

Propor-se a estudar o desenvolvimento de crianças com deficiências é um desafio. Nesta investigação, as crianças possuem alterações orgânicas específicas, adicionais à deficiência visual, o que torna os casos ainda mais particulares. De forma geral, as observações levam a identificar problemas no desenvolvimento de crianças com deficiência visual, especialmente no caso de crianças cegas (CELESTE, 2006; PREISLER, 1997). Isso é ainda mais sério se as crianças tiverem outros comprometimentos (OPHIR-COHEN et al., 2005; HOBSON et al., 1997; ERIN, 1996; WARREN, 1994). Entretanto, ao analisar os episódios aqui retratados, verifica-se que, a partir das contribuições dos diferentes autores aqui apresentados (SMOLKA, 2000; VYGOTSKY, 1997; 1998; 2000; FRANCHI, 1992; GERALDI, 1990), foi possível destacar processos de desenvolvimento em crianças que apresentam uma instabilidade que, muitas vezes, é vista exclusivamente como sinônimo de atraso. $\mathrm{O}$ objetivo das análises, portanto, foi o de buscar mostrar indícios de desenvolvimento, ainda que esses apareçam em momentos distintos e de forma não linear.

Não se exclui aqui o fato de que as crianças estudadas apresentam características que são geralmente observadas em crianças menores, ou, mesmo, que apresentam modos de agir considerados alterados em relação às expectativas e ao observado em crianças de mesma faixa etária. O que se ressalta, neste trabalho, é que as teorias mencionadas se tornaram extremamente relevantes para dar sentido às ações de crianças cujo desenvolvimento se apresentava como extremamente 
comprometido. No caso dessas crianças, avaliações com base em padrões típicos tendem a identificar e mapear déficits. Além disso, indícios de apropriações de práticas sociais tendem a parecerem triviais, sem grande significado para o processo de desenvolvimento. $\mathrm{O}$ objetivo desta pesquisa foi o de ir no contra fluxo, e, ao invés de salientar os atrasos, destacar os indícios de desenvolvimento observados em contextos de interação, no caso, centralmente com adultos.

$\mathrm{O}$ que se verifica, nesses casos em que a instabilidade no processo de desenvolvimento é maior, é que os momentos de interação, mediação, (re) significação e atribuição de sentidos realizados nas práticas sociais com objetos culturalmente configurados, permeados pela/da/na linguagem, parecem tomar maior relevância, pois permitem emergir e tornar visíveis esses indícios de desenvolvimento, que nem sempre são percebidos ou ressaltados. A análise dos episódios à luz da concepção histórico-cultural de desenvolvimento permitiu que fossem atribuídos sentidos ao que a criança realiza e caracterizar aquilo que faz considerando-se os movimentos de produção de significação das ações da criança, no interior das dinâmicas interativas, como constitutivos de seu desenvolvimento. Levanta-se a hipótese de que o problema com essas crianças esteja mais relacionado a dificuldades na estabilização de processos de desenvolvimento, do que a atrasos, linearmente qualificados.

Analisando os casos apresentados, verifica-se que as crianças demonstraram ações nem sempre observadas em outros momentos. $O$ que isso revela? Que o processo de desenvolvimento é repleto de idas e vindas, de constantes (re)construções e (re)elaborações por parte dos sujeitos. E no caso de crianças com problemas orgânicos severos, como são os casos das crianças aqui retratadas, essa não linearidade se torna ainda mais proeminente. Revela também que o fato do desenvolvimento dessas crianças ser mais instável, não significa que ele não esteja ocorrendo. Não se pode afirmar com certeza de que nos momentos em que a criança não faz o que é proposto, ou não utiliza um objeto de forma convencional, ela não o saiba fazer (pois pode apresentar a ação solicitada em outro momento, em outra sessão de atendimento). Por outro lado, quando a criança demonstra usos mais convencionais ou realiza atividades de acordo com o que lhe é proposto, é possível afirmar que existem processos de apropriação de práticas sociais ocorrendo, ainda que não se tenha claro o que a criança entende ou não (VYGOTSKY, 1997; 1998; 2000).

As análises também permitiram que fossem observados diferentes modos de atuação dos adultos, que organizavam a situação, propunham atividades, atribuíam significados e davam sentido às ações da criança. Nos episódios relatados foi possível verificar que a atuação do adulto, sensível às ações da criança, teve grande importância no processo de apropriação de práticas sociais pela criança - seja no processo de significação (atribuindo sentido, explicando, orientando), seja no jogo interativo (ajudando a estabelecer contato entre pares, prolongando a duração da interação - uma vez que as crianças aqui retratadas raramente 
interagem com seus pares), seja auxiliando ou dando suporte. É nessas práticas, nas relações significativas, que o sujeito se constitui.

\section{CONSIDERAÇÕES FINAIS}

Considerando-se que esta pesquisa evidenciou a importância dos processos de interação e significação no desenvolvimento e na constituição dos sujeitos, sugere-se que centrar o trabalho nesses processos seja um caminho para promover o desenvolvimento de crianças com necessidades especiais. Levando-se em conta que a atenção às ações da criança se destacou nas análises como lugar de significação e possibilidade de interação, ressalta-se aqui a relevância desses momentos na experiência e vivência de práticas sociais em crianças que apresentam dificuldades em seu desenvolvimento social, afetivo, cognitivo e linguístico.

Retomando as concepções de Smolka (2000), se são as relações sociais nas quais o sujeito está envolvido que podem explicar seus modos de ser, agir, pensar e relacionar-se, propiciar a interação de crianças com pares ou adultos parece ser uma alternativa para criar oportunidades de apreensão de significados e apropriação de práticas sociais, que envolvem aspectos culturais. Esses momentos tornam-se lugares para se observar indícios de desenvolvimento e o que se evidencia como algo para se trabalhar (possíveis dificuldades).

Assumindo-se que as práticas sociais e os processos de interação estão imersos em uma malha de elementos de natureza semiótica, inter-relacionados dialeticamente, os objetos com os quais se trabalha e as atividades propostas nos contextos de interação adquirem grande importância. Nesse cenário, a linguagem aparece como aquela pela qual se constroem os sistemas de referência que permitem compreender as coisas do mundo e, dialeticamente, são os sistemas de referência que permitem que a linguagem ganhe sentido (FRANCHI, 1992). Dentro dessa perspectiva, as possibilidades de trabalho com crianças que nem sempre se utilizam da linguagem se ampliam, uma vez que os movimentos de produção de significação das ações da criança, no interior das dinâmicas interativas, passam também a serem vistos como constitutivos de seu desenvolvimento.

A partir das perspectivas teóricas aqui discutidas e das análises realizadas, houve a possibilidade de ampliar os conhecimentos sobre o desenvolvimento de crianças com necessidades especiais e sugerir estratégias de trabalho para promover seu desenvolvimento. Esta pesquisa, no entanto, trouxe apenas uma pequena contribuição. $\mathrm{O}$ desenvolvimento de crianças com necessidades especiais continua sendo um estudo desafiador. Ainda existem muitas questões a serem discutidas e trabalhadas. Tendo isso em vista, espera-se que novas pesquisas sejam desenvolvidas na área. 


\section{REFERÊNCIAS}

ALON, L. et al. Regulation Disorders Among Children with Visual Impairment a Controlled Study. Journal of Developmental and Physical Disabilities, Forest Grove, v.22, p.57-64, 2010.

BATISTA, C. G.; LAPLANE, A. L. F. Modalidades de atendimento especializado: o grupo de convivência de crianças com deficiência visual. In: MASINI, E. F. S. (Org.). A pessoa com deficiência visual: um livro para educadores. São Paulo: Vetor, 2007. p.85-111

BOSA, C. Atenção compartilhada e identificação precoce do autismo. Psicologia: Reflexão e Crítica, Porto Alegre, v.15, n.1, p.77-88, 2002.

BOSA, C.; CALLIAS, M. Autismo: breve revisão de diferentes Abordagens. Psicologia: Reflexão e Crítica, Porto Alegre, v. 13, n. 1, p. 167-177, 2000.

CARVALHO, A.M.A.; PEDROSA, M.I. Cultura no grupo de brinquedo. Estudos de Psicologia, Natal, v.7, n.1, p.181-188, 2002.

CELESTE, M. Play Behaviors and social interactions of a child who is blind: in theory and practice. Journal of Visual Impairment \& Blindness, v.100, n.2, p.75-90, 2006.

ERIN, J. Children with multiple and visual disabilities. In: HOLBROOK, M. C. Children with visual impairments. USA: Woodbine House, 1996.

FRANCHI, C. Linguagem - atividade constitutiva. Cadernos de Estudos Linguísticos, Campinas, v.22, p.9-39, 1992.

GERALDI, J.W. Portos de passagem. São Paulo: Martins Fontes, 1990.

GÓES, M.C.R. A abordagem microgenética na matriz histórico-cultural: uma perspectiva para o estudo da constituição da subjetividade. Cadernos Cedes, Campinas, v.20, n.50, 2000.

HOBSON, R. P. et al. 'Autism' revisited: the case of congenital blindness. In: LEWIS, V.; COLLINS, G. Blindness and psychological development in young children. UK: British Psychological Society, 1997.

LUDKE M.; ANDRÉ M. E. D. A. Pesquisa em educação: abordagens qualitativas. São Paulo: Editora Pedagógica e Universitária Ltda, 1986.

OPHIR-COHEN, M. et al. Emotional status and development in children who are visually impaired. Journal of Visual Impairment \& Blindness, Baltimore, v.99, n.8, p.478-485, 2005.

PREISLER, G. Social and emotional development of blind children: a longitudinal study. In: LEWIS, V.; COLLIS, G. M. (Org.). Blindness and psychological development in young children. Reino Unido: The British Psychological Society, 1997. p.69-85,

RODRÍGUEZ, C.; MORO, C. El mágico número três - cuando los niños aún no hablan. Paidós Ibérica, S.A, 1999.

SILVA, M. A.; BATISTA, C. G. Mediação Semiótica: estudo de caso de uma criança cega, com alterações no desenvolvimento. Psicologia: Reflexão e Crítica; v.20, n.1, p.148-56, 2007.

SINHA, C. Blending out of the background: play, props and staging in the material world. Journal of Pragmatics, Lancaster, v.37, p.1537-1554, 2005. 
SMOLKA, A. L. B. O (im)próprio e o (im)pertinente na apropriação das práticas sociais. Cadernos Cedes, Campinas, v.20, n.50, 2000.

VYGOSTKY, L.S. Concrete human psychology. Soviet Psychology, Moscou, v.27, n.2, p.5377, 1989.

. Obras Escogidas. Tradução de BLANK, J. G. Madrid: Visor, 1997. (Tradução espanhola dos originais russos de 1924 a 1934).

. A formação social da mente. Tradução de NETO, J. C.; BARRETO, L. S. M.;

AFECHER, S. C. 6. ed. São Paulo: Martins Fontes, 1998. (Tradução do texto em inglês de originais russos até 1934).

. A construção do pensamento e da Linguagem. Tradução de BEZERRA, P. São Paulo: Martins Fontes, 2000. (Tradução do original russo Pensamento e Linguagem).

WARREN, D.H. Blindness and Children: an individual differences approach. EUA: Cambridge University Press, 1994.

WILLIS, C. E.; BEIGHTON, P. Ectodermal dysplasia with blindness in sibs on the island of Rodrigues. Med Genet, Londres, v.29, p.323-325, 1992.

WOLF-SCHEIN, E. G. Considerations in assessment of children with severe disabilities including deaf-blindness and autism. International Journal of Disability, Development and Education, v.45, n.1, p.35-55, 1998.

Recebido em: 23/12/2010

Reformulado em: 08/07/2011

Aprovado em: 14/10/2011 
CAVAlCANTE, T. C. F. 